\title{
Socioeconomic and modifiable predictors of blood pressure control for hypertension in primary care attenders in the Western Cape, South Africa
}

\author{
N Folb, ${ }^{1,2,3}$ MB ChB, MRCGP (UK); M O Bachmann, ${ }^{4}$ MB ChB, PhD, FFPH (UK); E D Bateman, ${ }^{1,2,3}$ MB ChB, MD, FRCP (UK); \\ K Steyn, ${ }^{2,3}$ MSc, NED, MD; N S Levitt, ${ }^{2,3}$ MB ChB, MD, FCP (SA); V Timmerman, ${ }^{1} \mathrm{PhD}$; C Lombard, ${ }^{5} \mathrm{MSc}$, PhD; \\ T A Gaziano, ${ }^{3,6} \mathrm{MD}, \mathrm{MSc}$; L R Fairall, ${ }^{1,2,3} \mathrm{MB} \mathrm{ChB}, \mathrm{PhD}$ \\ ${ }^{1}$ University of Cape Town Lung Institute, Groote Schuur Hospital, Cape Town, South Africa \\ ${ }^{2}$ Department of Medicine, Faculty of Health Sciences, University of Cape Town, South Africa \\ ${ }^{3}$ Chronic Disease Initiative for Africa, Department of Medicine, Faculty of Health Sciences, University of Cape Town, South Africa \\ ${ }^{4}$ Department of Population Health and Primary Care, Norwich Medical School, Faculty of Medicine and Health, University of East Anglia, UK \\ ${ }^{5}$ Biostatistics Unit, South African Medical Research Council, Cape Town, and School of Public Health and Family Medicine, \\ Faculty of Health Sciences, University of Cape Town, South Africa \\ ${ }^{6}$ Division of Cardiovascular Medicine, Brigham \& Women's Hospital, Boston, Mass., USA
}

Corresponding author: N Folb (naomi.folb@uct.ac.za)

\begin{abstract}
Background. Low socioeconomic status is associated with the risk of hypertension. There are few reports of the effect of socioeconomic and potentially modifiable factors on the control of hypertension in South Africa (SA).

Objectives. To investigate associations between patients' socioeconomic status and characteristics of primary healthcare facilities, and control and treatment of blood pressure in hypertensive patients.

Methods. We enrolled hypertensive patients attending 38 public sector primary care clinics in the Western Cape, SA, in 2011, and followed them up 14 months later as part of a randomised controlled trial. Blood pressure was measured and prescriptions for antihypertension medications were recorded at baseline and follow-up. Logistic regression models assessed associations between patients' socioeconomic status, characteristics of primary healthcare facilities, and control and treatment of blood pressure.

Results. Blood pressure was uncontrolled in 60\% (1 917/3 220) of patients at baseline, which was less likely in patients with a higher level of education $(p=0.001)$ and in English compared with Afrikaans respondents ( $p=0.033)$. Treatment was intensified in $48 \%(892 / 1872)$ of patients with uncontrolled blood pressure at baseline, which was more likely in patients with higher blood pressure at baseline $(p<0.001)$, concurrent diabetes $(p=0.013)$, more education $(p=0.020)$, and those who attended clinics offering off-site drug supply $(p=0.009)$, with a doctor every day $(p=0.004)$, or with more nurses $(p<0.001)$.

Conclusion. Patient and clinic factors influence blood pressure control and treatment in primary care clinics in SA. Potential modifiable factors include ensuring effective communication of health messages, providing convenient access to medications, and addressing staff shortages in primary care clinics.
\end{abstract}

S Afr Med J 2016;106(12):1241-1246. DOI:10.7196/SAMJ.2016.v106i12.12005

High blood pressure is a leading cause of mortality and disability worldwide. ${ }^{[1]}$ In South Africa (SA), the prevalence of hypertension is estimated to be $21 \%$ in people aged $\geq 15$ years, ${ }^{[2]}$ and in a survey performed in public sector clinics in four provinces, hypertension was the most common diagnosis and reason for attendance. ${ }^{[3]}$ Several reports point to poor levels of blood pressure control and low levels of treatment. ${ }^{[4-6]}$

The burden of ill-health and of chronic diseases such as hypertension is strongly influenced by socioeconomic status. ${ }^{[7-9]} \mathrm{Few}$ publications have considered the impact of socioeconomic status on control of blood pressure and potentially modifiable factors associated with better blood pressure control in SA.

We studied a cohort of primary care clinic attenders with hypertension, recruited as part of a randomised controlled trial. The objective of this study was to investigate the extent to which patientrelated and socioeconomic factors, and characteristics of primary healthcare facilities, were associated with blood pressure control and with intensified hypertension treatment in patients with uncontrolled blood pressure.

\section{Methods}

\section{Study population}

The study population comprised adults $\geq 18$ years of age residing in the Eden District and two sub-districts in the Overberg, Western Cape, SA, who were participating in a pragmatic cluster randomised controlled trial to evaluate the effectiveness of a training programme for primary healthcare providers in the use of the Primary Care 101 (PC101) patient management tool. ${ }^{[10,11]}$ The study focused on improving the quality of care for four specified chronic diseases. The study population for this article was confined to patients who reported current use of a medication for hypertension, in both the intervention and control arms.

Patients were recruited from the largest 38 public sector primary care clinics in the Eden District and two Overberg sub-districts, each of which report more than 10000 client visits per year. Services in these clinics are nurse led, with varying levels of doctor involvement (often part-time). The communities served by these clinics are characterised by high levels of unemployment and socioeconomic deprivation, typical of many rural and small urban areas in SA. 
Patients who reported current use of a medication for hypertension were eligible for inclusion if they were likely to reside in the same health district for the duration of the study and were capable of engaging in an interviewer-administered questionnaire in their preferred language (English, Afrikaans or isiXhosa). Participants were recruited in clinic waiting rooms and, if eligible, provided informed consent prior to study procedures. Their blood pressure was measured and prescription data were collected at baseline (in 2011) and 14 months later. ${ }^{[1]}$

\section{Data collection}

At baseline, trained fieldworkers administered an electronic questionnaire and took clinical measurements. The baseline questionnaire covered demographic characteristics, level of education, employment status, income during the last month, language, and presence of comorbidities.

Fieldworkers photocopied all available prescription charts for the year preceding the interview. These were reviewed by a medically qualified researcher (NF) to identify hypertension medications prescribed at baseline.

Blood pressure was measured with the patient in the seated position after at least 5 minutes' rest, using a calibrated automatic monitor, the Omron M6 Comfort (OMRON Healthcare, The Netherlands). The second and third of three readings were averaged and recorded. ${ }^{[12]}$

Follow-up assessment involved completion of a questionnaire, clinical measurements and collection of prescription data in a similar manner to assessment at baseline. Baseline data were collected from March to November 2011 and follow-up data from May to December 2012 .

Uncontrolled blood pressure was defined as systolic blood pressure $\geq 140 \mathrm{mmHg}$ or diastolic blood pressure $\geq 90 \mathrm{mmHg}$. The assessment of treatment intensification for hypertension was based on treatment steps in the PC101 clinical management tool, which conformed to prescribing policies of the relevant health authorities, an approach used in previous reported studies employing treatment intensification as an outcome measure. ${ }^{[10,13,14]}$ Treatment intensification was defined as: $(i)$ an increase in dose of an antihypertensive; or (ii) a switch to an antihypertensive in another medication class; or (iii) the addition of an antihypertensive in the same or different class; or (iv) a switch of an antihypertensive within a class but at a higher dose; or $(v)$ the addition of aspirin; or $(v i)$ the addition of or increase in statin dose.

\section{Statistical methods}

The statistical analyses investigated associations between participants' health and socioeconomic indicators, their blood pressure control, characteristics of their clinics, and intensification of hypertension treatment during the study.

Differences in the characteristics of patients with and without blood pressure control at baseline, and of their clinics, were first tested with logistic regression models, with control as outcome, each characteristic as the explanatory variable, and a separate model for each characteristic. The patient and clinic characteristics included in these models are shown in Table 1.

Independent predictors of uncontrolled blood pressure at baseline and at follow-up were investigated with multiple logistic regression models, first including all potential predictors as covariates, and then retaining only those covariates that were independent predictors at the $5 \%$ significance level. Models to identify predictors of change in hypertension control between baseline and follow-up used analysis of covariance (ANCOVA), with control at follow-up as outcome and control at baseline as a covariate. This was done to account for regression to the mean.

Analyses identifying predictors of treatment intensification among patients with uncontrolled blood pressure at baseline included the same patient and clinic characteristics used in the blood pressure control models, and also baseline blood pressure level. We report on the full model, including all characteristics as covariates, and a restricted model, including only covariates that were independent predictors at the $5 \%$ significance level. These analyses were repeated in all patients, including those with controlled blood pressure at baseline.

In all analyses the study's cluster sampling design was accounted for in regression models with robust adjustment for intraclinic cluster correlation of outcomes, using Stata version 13.0 (StataCorp LP, USA) statistical software. The $p$-values for education were estimated by modelling education as a continuous variable, with values of 0,1 , 2 and 3 indicating higher levels of education. A $p$-value $\leq 0.05$ was considered statistically significant. The intervention v. the control arm of the randomised controlled trial was included as a covariate in all longitudinal analyses to account for the study design.

The trial was registered with Current Controlled Trials (ISRCTN 20283604). Ethical approval for the trial was obtained from the University of Cape Town Human Research Ethics Committee (HREC 119/2010) and the Western Cape Provincial Department of Health. All participants provided written informed consent to participate in the study.

\section{Results}

A total of 3220 participants with hypertension and baseline blood pressure readings were enrolled in the study, of whom $91 \%$ were interviewed at follow-up. Prescription data were available for 3197 (99\%) participants at baseline and for 3137 (97\%) at follow-up.

The sociodemographic characteristics of patient and clinic participants at baseline, and the difference between patients with and without blood pressure control at baseline, are reported in Table 1. The majority of participants $(75 \%)$ were women and half were aged $\geq 50$ years. The majority of participants had not completed secondary school education (56\%), were unemployed (77\%) and were receiving a welfare grant $(61 \%)$. The average monthly income of participants, of whom 23\% reported having no income, was ZAR1 105 (USD160).

Sixty per cent (1 917) of participants had uncontrolled blood pressure at baseline. Table 1 shows that at baseline a higher level of formal education was associated with blood pressure control ( $p=0.001$ ), and participants with controlled blood pressure were more likely to have secondary or tertiary education ( $47 \%$ of patients with controlled v. $42 \%$ with uncontrolled blood pressure). Participants with controlled blood pressure were more likely to attend larger clinics ( $p=0.033$ ) or clinics with a larger complement of nurses $(p=0.037)$.

Logistic regression analyses identified independent associations between health and socioeconomic indicators and blood pressure control (Table 2). At baseline, a higher level of education, and English v. Afrikaans language, were associated with lower odds of uncontrolled blood pressure. There was no interaction between education and language $(p=0.76)$ when an interaction term was added to the model. At follow-up, patients with higher incomes had lower odds of uncontrolled blood pressure in the full model with all covariates. In the restricted model, from which all other covariates except baseline control and the trial arm were removed, this association became non-significant $(p=0.086)$. No clinic-related 


\begin{tabular}{|c|c|c|c|c|}
\hline Characteristics & $\begin{array}{l}\text { Patients }(N=3220), \\
n(\%)\end{array}$ & $\begin{array}{l}\text { BP controlled }{ }^{\star} \text { at } \\
\text { baseline }(N=1303), \\
n(\%)\end{array}$ & $\begin{array}{l}\text { BP uncontrolled at } \\
\text { baseline }(N=1917), \\
n(\%)\end{array}$ & $p$-value ${ }^{*}$ \\
\hline \multicolumn{5}{|l|}{ Participant characteristics } \\
\hline Age (years): mean (SD) ${ }^{\varsigma}$ & $54.81(12.0)$ & $54.36(12.5)$ & $55.11(11.7)$ & 0.092 \\
\hline Sex & & & & 0.546 \\
\hline Female & $2419(75.1)$ & $986(75.7)$ & $1433(74.8)$ & \\
\hline Male & $801(24.9)$ & $317(24.3)$ & $484(25.2)$ & \\
\hline Diabetes & $1538(47.8)$ & $647(49.7)$ & $891(46.5)$ & 0.162 \\
\hline Known cardiovascular disease & $848(26.3)$ & $347(26.6)$ & $501(26.1)$ & 0.698 \\
\hline Language & & & & 0.054 \\
\hline Afrikaans & $2732(84.8)$ & $1095(84.0)$ & $637(85.4)$ & \\
\hline isiXhosa & $220(6.8)$ & $79(6.1)$ & $141(7.4)$ & \\
\hline English & $268(8.3)$ & $129(9.9)$ & $139(7.3)$ & \\
\hline Highest education & $n=2938$ & $n=1184$ & $n=1754$ & 0.001 \\
\hline None & $242(8.2)$ & $86(7.3)$ & $156(8.9)$ & \\
\hline Primary & $1397(47.5)$ & $538(45.4)$ & $589(49.0)$ & \\
\hline Secondary & $1244(42.3)$ & $526(44.4)$ & $718(40.9)$ & \\
\hline Tertiary & $55(1.87)$ & $34(2.9)$ & $21(1.2)$ & \\
\hline Total monthly income (ZAR): mean (SD) & $\begin{array}{l}1104.9\left(\begin{array}{ll}1 & 120.0\end{array}\right) \\
(n=3215)\end{array}$ & $\begin{array}{l}1142.5(1226.1) \\
(n=1301)\end{array}$ & $\begin{array}{l}1079.3(1041.2) \\
(n=1914)\end{array}$ & 0.125 \\
\hline Unemployed & $\begin{array}{l}2472(76.9) \\
(n=3215)\end{array}$ & $\begin{array}{l}1002(77.0) \\
(n=1301)\end{array}$ & $\begin{array}{l}1470(76.8) \\
(n=1914)\end{array}$ & 0.865 \\
\hline Welfare grant received & $\begin{array}{l}1967(61.2) \\
(n=3215)\end{array}$ & $\begin{array}{l}808(62.1) \\
(n=1301)\end{array}$ & $\begin{array}{l}1159(60.6) \\
(n=1914)\end{array}$ & 0.382 \\
\hline \multicolumn{5}{|l|}{ Clinic characteristics } \\
\hline Pharmacist in clinic & $1487(46.2)$ & $622(47.7)$ & $865(45.1)$ & 0.456 \\
\hline Drug supply available away from clinic & $2124(66.0)$ & $840(64.5)$ & $1284(67.0)$ & 0.437 \\
\hline Doctor at clinic every day & $1333(41.4)$ & $562(43.1)$ & $771(40.2)$ & 0.405 \\
\hline Clinic location & & & & 0.951 \\
\hline Urban & $1977(61.4)$ & $804(61.7)$ & $1173(61.2)$ & \\
\hline Peri-urban & $511(15.9)$ & $202(15.5)$ & $309(16.1)$ & \\
\hline Rural & $732(22.7)$ & $297(22.8)$ & $435(22.7)$ & \\
\hline Clinic patients/year/1 0000: mean (SD) ${ }^{\varsigma}$ & $3.7(3.7)$ & $3.9(3.9)$ & $3.6(3.5)$ & 0.033 \\
\hline Clinic nurses: mean $(\mathrm{SD})^{\varsigma}$ & $5.4(2.9)$ & $5.6(2.9)$ & $5.2(2.9)$ & 0.037 \\
\hline Clinic nurses $(n)$ & & & & 0.051 \\
\hline$<5$ & $1564(48.6)$ & $581(44.6)$ & $983(51.3)$ & \\
\hline$\geq 5$ & $1656(51.4)$ & $722(55.4)$ & $934(48.7)$ & \\
\hline Intervention v. control clinic & & & & 0.234 \\
\hline Intervention & $1553(48.2)$ & $660(50.7)$ & $893(6.6)$ & \\
\hline Control & $1667(51.8)$ & $643(49.4)$ & $1024(53.4)$ & \\
\hline
\end{tabular}

factors were independently associated with blood pressure control at baseline or at follow-up.

Hypertension treatment was intensified in $48 \%$ of 1872 patients in whom blood pressure was uncontrolled at baseline. In participants whose blood pressure was uncontrolled at baseline, treatment intensification was independently more probable in those who had a higher mean systolic blood pressure at baseline $(p<0.001)$, diabetes $(p=0.013)$, a higher level of education $(p=0.020)$, and attended a clinic with the option of off-site drug supply $(p=0.009)$, with a doctor present daily $(p=0.004)$, with a larger number of nurses $(p<0.001)$ or in the intervention arm of the trial $(p<0.001)$ (Table 3). There was no interaction between education and language $(p=0.92)$ when an interaction term was added to the model. When all patients, including those with controlled blood pressure at baseline, were included in the analysis, the association with number of clinic nurses remained significant.

\section{Discussion}

This study, performed in a cohort of hypertensive low-income patients with generally low levels of formal education attending public sector 


\begin{tabular}{|c|c|c|c|c|c|c|c|c|c|}
\hline \multirow{2}{*}{$\begin{array}{l}\text { Outcome } \\
\text { Explanatory baseline } \\
\text { variable }\end{array}$} & \multicolumn{3}{|c|}{$\begin{array}{l}\text { Uncontrolled } \mathrm{BP} \text { at baseline: } \\
\text { full model }(N=3220)\end{array}$} & \multicolumn{3}{|c|}{$\begin{array}{l}\text { Uncontrolled } \mathrm{BP}^{*} \text { at baseline: } \\
\text { limited model }(N=3220)\end{array}$} & \multicolumn{3}{|c|}{$\begin{array}{l}\text { Uncontrolled } \mathrm{BP}^{*} \text { at follow-up: } \\
\text { full model }(N=3220)\end{array}$} \\
\hline & OR & $95 \% \mathrm{CI}$ & $p$-value & OR & $95 \%$ CI & $p$-value & OR & $95 \%$ CI & $p$-value \\
\hline Age (per year) & 1.01 & $1.00-1.01$ & 0.170 & & & & 1.00 & $0.99-1.01$ & 0.469 \\
\hline Male v. female & 1.08 & $0.90-1.30$ & 0.412 & & & & 1.11 & $0.95-1.29$ & 0.178 \\
\hline $\begin{array}{l}\text { Uncontrolled blood } \\
\text { pressure* }\end{array}$ & & & & & & & 3.88 & $3.30-4.56$ & $<0.001$ \\
\hline Diabetes & 0.93 & $0.76-1.14$ & 0.508 & & & & 1.04 & $0.88-1.22$ & 0.654 \\
\hline $\begin{array}{l}\text { Known cardiovascular } \\
\text { disease }\end{array}$ & 0.98 & $0.84-1.13$ & 0.758 & & & & 1.05 & $0.86-1.28$ & 0.616 \\
\hline Language & & & $0.008^{\dagger}$ & & & $0.033^{\dagger}$ & & & $0.794^{\dagger}$ \\
\hline Afrikaans (reference) & 1.00 & & & 1.00 & & & 1.00 & & \\
\hline isiXhosa & 1.38 & $0.99-1.94$ & 0.057 & 1.11 & $0.86-1.44$ & 0.432 & 1.10 & $0.76-1.59$ & 0.623 \\
\hline English & 0.78 & $0.55-1.09$ & 0.145 & 0.74 & $0.57-0.96$ & 0.026 & 0.93 & $0.60-1.42$ & 0.724 \\
\hline Highest education & & & $0.002^{\ddagger}$ & & & $0.001^{*}$ & & & $0.822^{\ddagger}$ \\
\hline None (reference) & 1.00 & & & 1.00 & & & 1.00 & & \\
\hline Primary & 0.89 & $0.67-1.19$ & 0.439 & 0.88 & $0.68-1.16$ & 0.367 & 1.17 & $0.87-1.57$ & 0.294 \\
\hline Secondary & 0.77 & $0.57-1.03$ & 0.081 & 0.76 & $0.58-0.99$ & 0.042 & 1.08 & $0.80-1.46$ & 0.623 \\
\hline Tertiary & 0.33 & $0.17-0.65$ & 0.001 & 0.35 & $0.18-0.68$ & 0.002 & 1.04 & $0.56-1.92$ & 0.905 \\
\hline $\begin{array}{l}\text { Total monthly income } \\
\text { (ZAR) }\end{array}$ & 0.97 & $0.88-1.06$ & 0.441 & & & & 0.90 & $0.82-0.99$ & 0.027 \\
\hline Unemployed v. employed & 0.92 & $0.74-1.12$ & 0.368 & & & & 0.82 & $0.64-1.06$ & 0.128 \\
\hline Welfare grant received & 0.91 & $0.75-1.12$ & 0.382 & & & & 0.99 & $0.80-1.23$ & 0.962 \\
\hline Pharmacist in clinic & 1.01 & $0.70-1.46$ & 0.944 & & & & 1.00 & $0.76-1.33$ & 0.985 \\
\hline $\begin{array}{l}\text { Drug supply available away } \\
\text { from clinic }\end{array}$ & 1.19 & $0.86-1.66$ & 0.297 & & & & 0.80 & $0.57-1.13$ & 0.206 \\
\hline Doctor at clinic every day & 1.10 & $0.80-1.52$ & 0.541 & & & & 0.99 & $0.68-1.45$ & 0.978 \\
\hline Clinic location & & & $0.760^{\dagger}$ & & & & & & $0.623^{\dagger}$ \\
\hline Urban (reference) & 1.00 & & & & & & 1.00 & & \\
\hline Peri-urban & 1.02 & $0.74-1.42$ & 0.900 & & & & 0.84 & $0.57-1.22$ & 0.357 \\
\hline Rural & 0.87 & $0.56-1.34$ & 0.528 & & & & 0.97 & $0.65-1.45$ & 0.868 \\
\hline Clinic patients/year/1 000 & 1.03 & $0.98-1.08$ & 0.235 & & & & 1.00 & $0.94-1.06$ & 0.992 \\
\hline Clinic nurses $(n)$ & 0.93 & $0.87-1.01$ & 0.079 & & & & 0.98 & $0.89-1.07$ & 0.594 \\
\hline $\begin{array}{l}\text { Intervention v. control } \\
\text { clinic }\end{array}$ & & & & & & & 1.06 & $0.76-1.48$ & 0.748 \\
\hline $\begin{array}{l}\mathrm{OR}=\text { odds ratio; } \mathrm{CI}=\text { confidence inte } \\
\text { Uncontrolled BP: systolic BP } \geq 140 \mathrm{~m} \\
\text { 'Wald test for all categories of variable } \\
\text { 'Test for trend. }\end{array}$ & $\begin{array}{l}\text { erval. } \\
\text { mitg or } \\
\text { e. }\end{array}$ & tolic BP $\geq 90 \mathrm{~mm}$ & & & & & & & \\
\hline
\end{tabular}

primary care clinics, confirms both patient and clinic-related factors that are associated, first, with the likelihood of blood pressure control (patient factors), and secondly, treatment intensification during the study period (patient and clinic-related factors). The importance of these findings is that some of these predictors may be modifiable, and should be considered in the planning of chronic disease control strategies and in the organisation of clinical services.

Patient factors associated with uncontrolled blood pressure at baseline included lower levels of education and communication in either isiXhosa or Afrikaans, rather than English. These associations need to be interpreted with caution for several reasons. First, while statistically significant, the absolute differences in blood pressure control associated with these risk factors were relatively small, reflecting the large sample size. Secondly, the association with patients' choice of language may have been influenced by issues relating to the conduct of the trial. Communication might have been poor, as not all interviewers were fluent in isiXhosa. Furthermore, language selection might serve as a proxy for factors not measured in this study, such as household conditions, informal education, and less prior exposure to health messages in patients' language of choice. Health literacy has complex associations, extending beyond formal education, and is rooted in the conditions under which patients live and the support they receive to accept and adhere to health advice. Murphy et al., ${ }^{[15]}$ in a qualitative study of hypertensive and diabetic patients attending three public sector community health centres in Cape Town, concluded that patients experienced 'multiple impediments to effective self-management and behaviour change, including poor health literacy, a lack of self-efficacy and perceived social support'. Although the introduction of PC101 seeks to address some of these needs, the results at baseline in our study are consistent with this assessment.

Perhaps more relevant are the features associated with treatment intensification, as the latter is likely to result in improved health outcomes in patients with hypertension. Again, in our study, a lower level of formal education was associated with a lower probability of treatment intensification. This finding might reflect 


\begin{tabular}{|c|c|c|c|c|c|c|}
\hline \multirow{2}{*}{$\begin{array}{l}\text { Outcome } \\
\text { Explanatory baseline variable }\end{array}$} & \multicolumn{3}{|c|}{$\begin{array}{l}\text { Treatment intensification of HPT if } \\
\text { uncontrolled BP at baseline: } \\
\text { full model }^{*}(N=1872)\end{array}$} & \multicolumn{3}{|c|}{$\begin{array}{l}\text { Treatment intensification of HPT } \\
\text { if uncontrolled BP at baseline:" } \\
\text { limited model }{ }^{+}(N=1872)\end{array}$} \\
\hline & OR & 95\% CI & $p$-value & OR & 95\% CI & $p$-value \\
\hline \multicolumn{7}{|l|}{ Patient characteristics } \\
\hline Age (per year) & 1.00 & $0.98-1.01$ & 0.391 & & & \\
\hline Male v. female & 0.94 & $0.74-1.21$ & 0.650 & & & \\
\hline Mean systolic BP & 1.01 & $1.01-1.02$ & $<0.001$ & 1.01 & $1.01-1.02$ & $<0.001$ \\
\hline Diabetes & 1.30 & $1.05-1.62$ & 0.018 & 1.31 & $1.06-1.62$ & 0.013 \\
\hline Known cardiovascular disease & 0.97 & $0.74-1.28$ & 0.835 & & & \\
\hline Language & & & $1.00^{\ddagger}$ & & & \\
\hline Afrikaans (reference) & 1.01 & & & & & \\
\hline isiXhosa & 0.78 & $0.67-1.50$ & 0.980 & & & \\
\hline English & 1.01 & $0.70-1.47$ & 0.946 & & & \\
\hline Highest education & & & $0.040^{\varsigma}$ & & & $0.020^{5}$ \\
\hline None (reference) & 1.00 & & & 1.00 & & \\
\hline Primary & 1.50 & $0.98-2.27$ & 0.059 & 1.45 & $0.97-2.17$ & 0.072 \\
\hline Secondary & 1.63 & $1.05-2.54$ & 0.030 & 1.63 & $1.07-2.49$ & 0.024 \\
\hline Tertiary & 1.95 & $0.66-5.74$ & 0.228 & 2.24 & $0.78-6.43$ & 0.134 \\
\hline Total monthly income & 1.04 & $0.91-1.18$ & 0.565 & & & \\
\hline Unemployed v. employed & 1.12 & $0.86-1.44$ & 0.402 & & & \\
\hline Welfare grant received & 0.91 & $0.70-1.19$ & 0.500 & & & \\
\hline \multicolumn{7}{|l|}{ Clinic characteristics } \\
\hline Pharmacist in clinic & 0.78 & $0.54-1.13$ & 0.192 & & & \\
\hline Drug supply available away from clinic & 1.40 & $1.06-1.86$ & 0.018 & 1.44 & $1.10-1.89$ & 0.009 \\
\hline Doctor at clinic every day & 1.73 & $1.25-2.40$ & 0.001 & 1.64 & $1.17-2.31$ & 0.004 \\
\hline Clinic location & & & $0.070^{\ddagger}$ & & & \\
\hline Urban (reference) & 1.00 & & & & & \\
\hline Peri-urban & 1.05 & $0.74-1.48$ & 0.779 & & & \\
\hline Rural & 0.66 & $0.45-0.97$ & 0.034 & & & \\
\hline Clinic patients/year/1 000 & 0.95 & $0.89-1.01$ & 0.089 & & & \\
\hline Clinic nurses $(n)$ & 1.22 & $1.10-1.34$ & $<0.001$ & 1.15 & $1.08-1.23$ & $<0.001$ \\
\hline Intervention v. control clinic & 1.80 & $1.34-2.40$ & $<0.001$ & 1.78 & $1.31-2.41$ & $<0.001$ \\
\hline 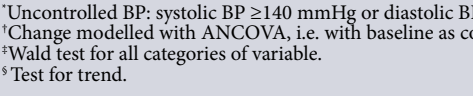 & & & & & & \\
\hline
\end{tabular}

the fact that effective communication and health literacy increase the likelihood of treatment changes - whether through increased willingness of clinicians to change treatment, or patients to accept it. ${ }^{[16]}$ Of concern, and contrary to expectations, is that the known presence of cardiovascular disease was not associated with treatment intensification, suggesting that clinicians missed the opportunity to provide secondary prevention for cardiovascular events. However, higher blood pressure and comorbid diabetes did increase the likelihood of treatment intensification, which is clinically appropriate.

The finding that housing density, receipt of welfare grants and total monthly income did not predict blood pressure control or treatment intensification may reflect the relative homogeneity of the study population, the majority of whom were poor (mean monthly income ZAR1 100 and 98\% earning less than ZAR5 000 per month) and 61\% receiving welfare grants. It is also partly because these factors are associated with education and language, which were controlled for.

An increased risk of hypertension has previously been associated with low socioeconomic indicators, with associations particularly evident for level of education. ${ }^{[8]}$ In SA, a higher level of education has been found to predict lower values of both diastolic and systolic blood pressure in women, while higher income predicted lower systolic blood pressure. ${ }^{[9]}$ Interestingly, this did not hold true for men. Our study, which comprised predominantly women, adds new evidence for an association between low levels of education and poorer hypertension control and treatment intensification in SA.

The poor levels of blood pressure control in this study $(60 \%$ of participants uncontrolled) are in keeping with previous studies. A 1999 survey in 18 community health centres in the Cape Peninsula, SA, found that $67 \%$ of hypertensive patients had uncontrolled blood pressure (>140/90 mmHg). ${ }^{[5]}$ In a $2009-2010$ study of goldminers in Gauteng Province, SA, only $42 \%$ of patients diagnosed with hypertension had received antihypertensive medication, and $69 \%$ of those on antihypertensive medication were poorly controlled. ${ }^{[6]}$

Our study has several strengths. The sample size was large, high rates of follow-up were achieved, and a range of socioeconomic variables were investigated. Furthermore, the longitudinal design enabled analysis of change in control and treatment. There were, however, several limitations. Patients were included in the hypertension group on the basis of self-reported use of medication for hypertension. On review of baseline prescription records, evidence of hypertension 
treatment was not found in 5\% (153) of participants. Secondly, no assessments of adherence were performed at baseline - clinicians who suspected significant non-adherence may have elected not to intensify treatment. A further potential limitation was language of communication, i.e. the possibility that interviewers might not have communicated effectively in the participant's language of choice. Finally, the homogeneity (limited range of socioeconomic status) of the population may have limited the assessment of the impact of individual determinants of blood pressure control.

In spite of these limitations, our findings have implications for clinicians and policymakers. Health services need to be sensitive to the impact of socioeconomic factors, and, in particular, lower levels of education. Emphasis must be placed on effective communication in the patient's language of choice, using educational materials and programmes prepared and presented in forms that are appropriate to their levels of education and health literacy. Secondly, our study points to clinic factors that may be addressed to improve the care of hypertensive patients. Besides attempting to improve staffing of clinics (preferably with doctors in attendance), this includes off-site access to maintenance medications. The latter finding is likely to be relevant to the care of all chronic diseases, and points to the need for expansion of drug delivery services in SA. Together, these measures should be viewed as achievable opportunities for improving the management of hypertension in primary care in SA.

Acknowledgements. The authors thank all clinic nurses, doctors, managers, pharmacists and pharmacy assistants at participating study facilities; the Western Cape Department of Health; the Eden and Overberg district management; and Primary Care 101 trainers and fieldworkers.

Funding. This project has been funded in part with federal funds, National Heart, Lung, and Blood Institute, National Institutes of Health, Department of Health and Human Services (contract no.: HHSN268200900030C), USA. Funding was also received from United Health, USA; the Western Cape Department of Health, SA; the Department of Medicine, University of Cape Town, SA; the UK Department for International Development; and the University of Cape Town Lung Institute, SA. The funders had no role in study design, data collection and analysis, decision to publish, or preparation of the manuscript.

1. Lim SS, Vos T, Flaxman AD, et al. A comparative risk assessment of burden of disease and injury attributable to 67 risk factors and risk factor clusters in 21 regions, 1990-2010: A systematic analysis for the Global Burden of Disease Study 2010. Lancet 2012;380(9859):2224-2260. http://dx.doi.org/10.1016/ S0140-6736(12)61766-8

2. Steyn K, Gaziano TA, Bradshaw D, Laubscher R, Fourie J. Hypertension in South African adults: Results from the Demographic and Health Survey, 1998. J Hypertens 2001;19(10):1717-1725. http:// dx.doi.org/10.1097/00004872-200110000-00004

3. Mash B, Fairall L, Adejayan O, et al. A morbidity survey of South African primary care. PLoS ONE 2012;7(3):e32358. http://dx.doi.org/10.1371/journal.pone.0032358

4. Rayner B. Hypertension: Detection and management in South Africa. Nephron Clin Pract 2010;116(4):c269-c273. http://dx.doi.org/10.1159/000318788

5. Steyn K, Levitt NS, Patel M, et al. Hypertension and diabetes: Poor care for patients at community 5. Steyn K, Levitt NS, Patel M, et al. Hypertension and diabetes: Poor care for patients at community
health centres. S Afr Med J 2008;98(8):618-622. http://dx.doi.org/10.1080/22201009.2008.10872172

6. Maepe LM, Outhoff K. Hypertension in goldminers. S Afr Med J 2012;102(1):30-33.

7. Ataguba JE, Akazili J, McIntyre D. Socioeconomic-related health inequality in South Africa: Evidence from general household surveys. Int J Equity Health 2011;10(1):48. http://dx.doi.org/10.1186/14759276-10-48

8. Leng B, Jin Y, Li G, Chen L, Jin N. Socioeconomic status and hypertension: A meta-analysis. J Hypertens 2015;33(2):221-229. http://dx.doi.org/10.1097/HJH.0000000000000428

9. Cois A, Ehrlich R. Analysing the socioeconomic determinants of hypertension in South Africa: A structural equation modelling approach. BMC Public Health 2014;14:414. http://dx.doi. org/10.1186/1471-2458-14-414

10. Health Systems Trust. Primary Health Care 101. 2013. http://www.hst.org.za/publications/primaryhealth-care-101 (accessed 27 July 2016).

11. Folb N, Timmerman V, Levitt NS, et al. Multimorbidity, control and treatment of noncommunicable diseases among primary healthcare attenders in the Western Cape. S Afr Med J 2015;105(8):642-664. http://dx.doi.org/10.7196/SAMJnew.7882

12. Centers for Disease Control and Prevention. National Health and Nutrition Examination Survey (NHANES) Health Tech/Blood Pressure Procedures Manual. 2009. http://www.cdc.gov/nchs/data/ nhanes/nhanes_09_10/BP.pdf (accessed 30 May 2016).

13. Van Bruggen R, Gorter K, Stolk R, Klungel O, Rutten G. Clinical inertia in general practice: Widespread and related to the outcome of diabetes care. Fam Pract 2009;26(26):428-436. http://dx.doi. org/10.1093/fampra/cmp053

14. Schmittdiel JA, Uratsu CS, Karter AJ, et al. Why don't diabetes patients achieve recommended risk factor targets? Poor adherence versus lack of treatment intensification. J Gen Intern Med 2008;23(5):588-594

15. Murphy K, Chuma T, Mathews C, Steyn K, Levitt N. A qualitative study of the experiences of care and motivation for effective self-management among diabetic and hypertensive patients attending public sector primary health care services in South Africa. BMC Health Serv Res 2015;15:303. http.//dx doi org/10.1186/s12913-015-0969-y

16. Zolnierek KB, DiMatteo MR. Physician communication and patient adherence to treatment: A metaanalysis. Med Care 2009;47(8):826-634.

Accepted 26 September 2016. 